\title{
Ontogenesis of Nerve Growth Factor and Epidermal Growth Factor in Submaxillary Glands and Nerve Growth Factor in Brains of Immature Male Mice: Correlation with Ontogenesis of Serum Levels of Thyroid Hormones
}

\author{
P. WALKER, M. E. WEICHSEL, JR., ${ }^{(42)}$ D. EVELETH, AND D. A. FISHER \\ Department of Pediatrics, Harbor-UCLA Medical Center, 1000 West Carson Street, Torrance, California, USA
}

\begin{abstract}
Summary
Using specific and sensitive radioimmunoassays for nerve growth factor (NGF) and epidermal growth factor (EGF), we studied the developmental profile of NGF and EGF concentrations in male mouse submaxillary gland (SMG) from 2-60 days of age. We measured NGF concentrations in mouse cerebellum, cerebral cortex, and brain stem from ages 2-32 days. In addition, we assessed mouse serum thyroxine (T4) and triiodothyronine (T3) levels in seperate groups of animals ranging from 5-50 days of age. Mean SMG EGF content and concentration exceeded that of NGF between 2 and 18 days of age. At all subsequent ages, however, mean NGF and EGF content and concentration were similar. SMG NGF and EGF content were low at 2 days of age, decreased slightly through 8 days of age, and increased exponentially after 11 days of age with three phases of increase being apparent for both proteins. In the first phase, mean SMG NGF and EGF contents increased 2.4- and 2.3-fold respectively between 11 and 18 days of age. A second phase of increase was noted between 18 and 32 days when NGF and EGF increased 9845- and 7805-fold respectively. In phase three (32-60 days of age) more modest increases of 6.5-fold in mean NGF and EGF content were noted.
\end{abstract}

Cerebellar NGF concentrations increased from 681 to $2241 \mathrm{pg} /$ mg protein between ages 2 and 15 days and subsequently fell to a plateau level of $1304 \mathrm{pg} / \mathrm{mg}$ protein by age 18 days. Cerebral cortical NGF concentrations increased steadily from 251 to 1383 $\mathrm{pg} / \mathrm{mg}$ protein between ages 2 and 32 days, whereas brain stem NGF concentrations maintained a plateau averaging $1100 \mathrm{pg} / \mathrm{mg}$ protein.

Serum $\mathbf{T} 4$ concentrations in the mouse increased dramatically from $2.5 \mu \mathrm{g} / \mathrm{dl}$ at 5 days to a maximum of $8.1 \mu \mathrm{g} / \mathrm{dl}$ at 15 days, thereafter decreasing to a nadir $4.4 \mu \mathrm{g} / \mathrm{dl}$ by 40 days. Serum T3 concentrations followed a similar pattern, rising from $25 \mathrm{ng} / \mathrm{dl}$ on postnatal day 5 to $93 \mathrm{ng} / \mathrm{dl}$ on day 15 , with a subsequent decline to $63 \mathrm{ng} / \mathrm{dl}$ by day 30 . These results indicate a correlation between the increase in serum thyroid hormone levels in the mouse and the increases in SMG NGF and EGF levels and brain NGF levels between 5 and 32 days.

\section{Speculation}

We and others have demonstrated that thyroid hormones increase brain NGF concentrations and stimulate submaxillary gland NGF and EGF synthesis. The present results are compatible with the hypothesis that the early increase in circulating thyroid hormone concentrations in the mouse play an important role in the increase in cerebral and cerebellar NGF levels during the first 3 wk and the increase in SMG NGF and EGF concentrations between 11 and 32 days of age. The known increase in mouse serum testosterone to adult male levels between 4-12 wk of age may be a factor in the late increase in NGF and EGF elevations after 32 days of age.

Nerve growth factor (NGF) and epidermal growth factor (EGF) are found in highest concentrations in the submaxillary gland (SMG) of the adult male mouse $(13,22)$. Both proteins are found in peritubular cells $(32,35)$ and are released concomitantly into saliva $(16,27)$. Both have C-terminus arginine residues $(2,13)$ and exist in SMG as high molecular weight complexes with specific arginine esteropeptidase subunits (34). In addition, both NGF, and EGF are found in higher concentrations in male than in female glands. The concentration of both peptides in SMG is increased by androgens $(10,17)$. Bynny et al. (9) described the ontogenetic profile of radioimmunoassayable SMG EGF content from 15 days of age through adulthood. Aloe and Levi-Montalcini (3) have traced the developmental pattern of SMG NGF concentrations after 20 days using an in vitro bioassay. Murphy et al. (26) have suggested that NGF and EGF are present in equal concentrations in mature male mouse SMG; however, simultaneous measurements of SMG NGF and EGF concentrations during postnatal development in the mouse have not been conducted.

In earlier reports we have described significant concentrations of radioimmunoassayble NGF in brain tissue of adult and developing mice $(37,40)$ but have not developed a complete ontogenetic profile; moreover, we have found that brain tissue contains no EGF (41). The present report describes studies of the developmental profile of SMG NGF and EGF concentrations in male mice 2-60 days of postnatal age and of NGF in cerebrum, cerebellar and brain stem tissues. Because thyroxine has been shown to increase both SMG NGF and EGF concentrations and to increase brain NGF levels $(37,40)$ and because there are no available data describing the ontogenesis of serum thyroid hormone levels in the mouse, we also developed ontogenic profiles for serum thyroxine (T4) and triiodothyronine (T3) concentrations.

\section{MATERIALS AND METHODS}

Animals. Swiss-Webster mice were obtained from Simonsen Laboratories, Gilroy, CA. Animals were received 1-2 days before sacrifice and were housed in a temperature- $\left(24^{\circ} \pm 1^{\circ} \mathrm{C}\right)$ and light-controlled (14 h light) room. Humidity was not controlled. Litters of eight male pups were housed with the dams in single cages. Postweanling mice were housed five/cage. Male mice for SMG studies were killed at 2, 5, 8, 11, 17, 18, 21, 28, 32, 40, and 60 days of age. Pooling of SMG tissue was required for data 
points in the younger age groups in order to yield sufficient material for measurement. At all ages a minimum of eight samples or pools was used for each data point. Maternal influences were obviated by pooling across litters. Brain regions were studied in separate groups of male animals at ages $2,5,12,15,17,18,20$, and 32 days; brain tissue from three or two animals was pooled for each of 5-10 data points at early and later ages respectively. In a third set of experiments, trunk blood from mice killed at ages 5 , $10,15,20,25,30,40$ and 50 days was collected for determination of serum thyroxine (T4) and triiodothyronine (T3) concentrations. This blood was centrifuged at $5000 \mathrm{Xg}$ for $10 \mathrm{~min}$ at $4^{\circ} \mathrm{C}$ and the sera pooled. Serum from 32 animals was pooled for measurements at ages 5 and 10 days and from 16 animals at later ages. Between 6-8 serum pools then were used for each data point.

SMG's were removed on ice. Brains were removed on ice and immediately dissected into cerebral cortex (excluding cerebral white matter and hippocampal formation), cerebellum, and brain stem fractions (below the inferior colliculus). SMG and brain tissues were weighed and homogenized in 10 and 5 volumes, respectively, of phosphate buffered saline (PBS) pH 7.2 at $4^{\circ} \mathrm{C}$. The supernatant, recovered after centrifugation at $2,5000 \mathrm{Xg}$ for $30 \mathrm{~min}$ at $4^{\circ} \mathrm{C}$, was frozen pending radioimmunoassay (RIA) measurement of EGF and/or NGF.

RIA for NGF and EGF. NGF and EGF were purified from male mouse SMG $(25,31)$ and used as iodination and reference preparations. Both purified NGF and EGF yielded single bands on sodium dodecyl sulfate polyacrylamide gel electrophoresis. Supernatant NGF and EGF concentrations were measured by specific double antibody RIA techniques $(38,39)$. All samples were assayed at two dilutions in the same RIA run. The RIA for $\beta$-NGF can quantify $10-20 \mathrm{pg} \beta$-NGF and cross-reacts completely with the large molecular weight $(140,000) 7 \mathrm{~S}$ storage form of NGF in the SMG. The EGF RIA is sensitive to $20-30$ pg EGF (MW 6000) and also cross-reacts with the larger (MW 74,000) SMG storage form. Intraassay coefficients of variation for NGF and EGF were $7.5 \%$ and $6.1 \%$ respectively. Cross-reaction of NGF in the RIA for EGF was $0.009 \%$, and EGF cross-reaction in the NGF RIA was $<0.001 \%$. Submandibular gland renin did not cross-react in either RIA. Recoveries of added purified NGF and EGF from tissue homogenates approximated $100 \%$ and the dose response curve for the tissue extract of each hormone was parallel to the standard curve.

Supernatant protein concentrations were determined by the Folin-phenol method of Lowry et al. (24), using bovine serum albumin as standard.

RIA for T4 and T3. Mouse serum T4 was measured by the RIA method of Chopra (11); hypothyroid sheep serum with added Lthyroxine (Sigma) was used for standard curves. Serum T3 also was measured by RIA (12) using L-triiodothyronine (Sigma) as the reference preparation. $I^{125}$ labeled T4 and T3 were purchased from Nichols Institute, San Pedro, Calif.

\section{RESULTS}

Figure 1 illustrates the ontogenetic profile of male SMG NGF and EGF contents (ng/mg wet weight; upper panel) and SMG wet weight (lower panel) as a function of increasing postnatal age. Mean SMG NGF and EGF contents had virtually identical developmental patterns. Between 2-18 days of age, SMG EGF content exceeded that of NGF. After 21 days, however, mean SMG NGF and EGF contents were virtually indistinguishable.

Both mean NGF and EGF contents declined slightly from 2-8 days of age. After 11 days SMG NGF and EGF contents increased exponentially. Three major phases of increase were apparent for both proteins. Between 11-18 days both NGF and EGF content increased by 2.4 - and 2.3 -fold respectively to values similar to those observed at 2 days of age. Between 18-32 days of age, mean SMG NGF and EGF contents increased 9845- and 7805-fold, respectively. The third phase of increase occurred between 32-60 days when concentrations of NGF and EGF each increased some 6.5 times.
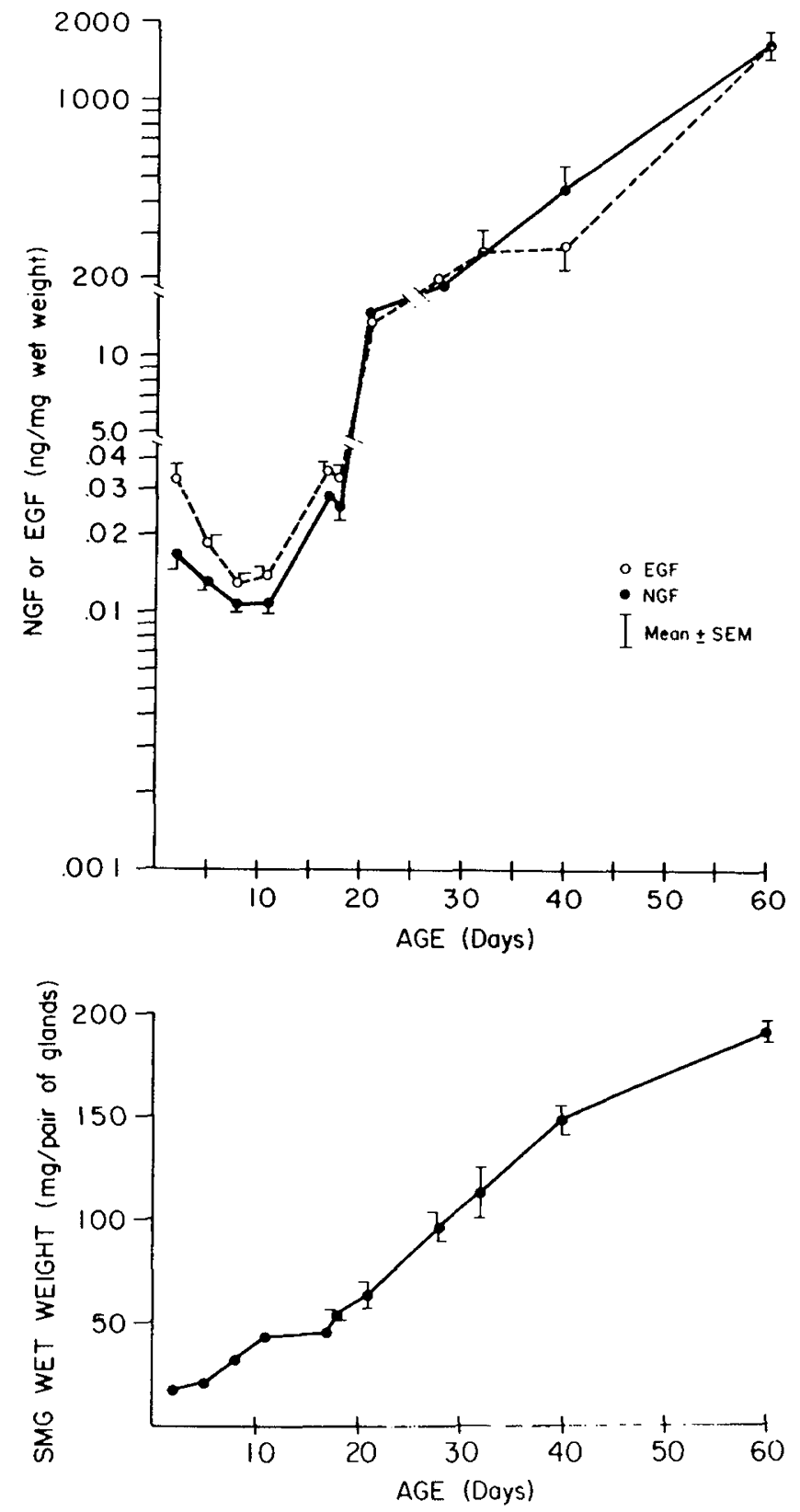

Fig. 1. (Upper panel) Developmental profile of SMG NGF (and EGF $\left(\mathrm{O}_{-}-\mathrm{O}\right)$ content in postnatal male mice. Data are plotted on logarithmic vertical axis. All data points comprise the mean \pm SE. See test for details of pooling methods. (Lower panel) Developmental profile of SMG weight in postnatal male mice. Data are plotted on an arithmetic vertical axis.

In contrast to the exponential increases in mean SMG NGF and EGF content, mean SMG weights (Fig. 1, lower panel) increased linearly some 8-10-fold between 2-60 days of age.

Examination of the increase in mean SMG NGF and EGF concentrations expressed relative to the SMG protein concentrations (Fig. 2 upper and lower panels) revealed similar developmental profiles. Mean SMG NGF and EGF concentrations decreased slightly between $2-11$ days, then increased to day 2 levels by 18 days of age. Marked increases in NGF and EGF concentrations were observed between 18 and 32 days of age and further increments were noted between 32-60 days of age. Mean SMG protein concentrations (Figure 2, lower panel) increased linearly in parallel with mean $S M G$ weights.

Figure 3 illustrates the ontogenetic profile of mean NGF levels in the three brain regions. Mean cerebellar NGF concentration 

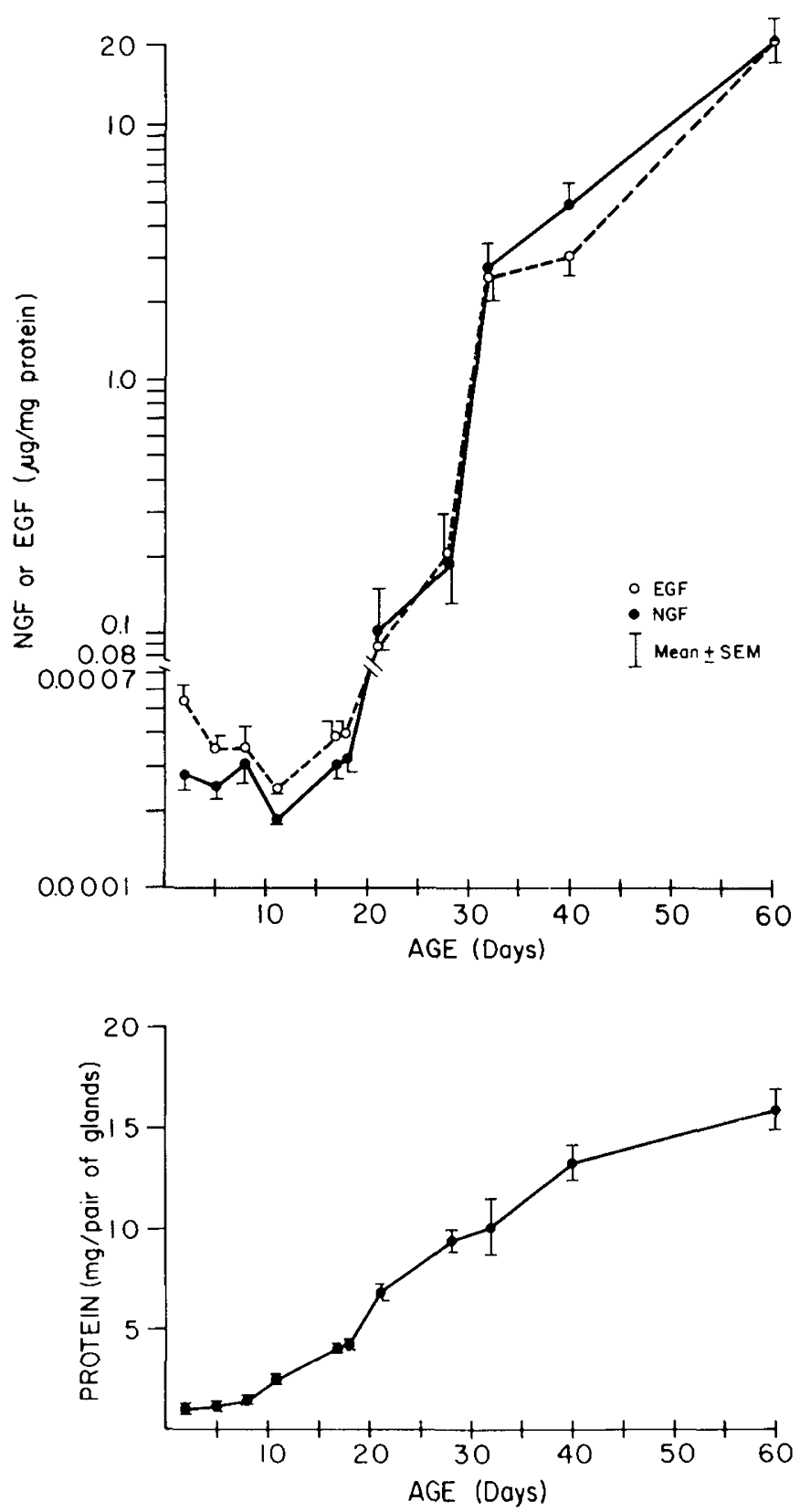

Fig. 2. (Upper panel) Ontogeny of SMG NGF (-) and EGF $(\mathrm{O}-\mathrm{-O}$ ) concentration in postnatal male mice. Data are plotted on a logarithmic vertical axis. All data points comprise the mean \pm SE. See text for details of pooling methods. (Lower panel) Developmental profile of SMG protein content in postnatal male mice. Data are plotted on an arithmetic vertical axis.

increased from $681-2241 \mathrm{pg} / \mathrm{mg}$ protein between ages 2-15 days, and subsequently fell to a plateau level of $1304 \mathrm{pg} / \mathrm{mg}$ protein by age 18 days. Cerebral cortical NGF increased steadily from 251 $1383 \mathrm{pg} / \mathrm{mg}$ protein between ages 2-32 days, whereas brain stem NGF concentrations maintained a plateau averaging $1100 \mathrm{pg} / \mathrm{mg}$ protein.

Figure 4 demonstrates that serum T4 concentrations increased dramatically from a mean of $2.5 \mu \mathrm{g} / \mathrm{dl}$ at age 5 days to a maximum concentration of $8.1 \mu \mathrm{g} / \mathrm{dl}$ at age 15 days. The mean level decreased to a nadir of $4.4 \mu \mathrm{g} / \mathrm{dl}$ by 40 days. Mean serum T3 concentrations followed a similar pattern, increasing from $25 \mathrm{ng} /$ $\mathrm{dl}$ on postnatal day 5 to $93 \mathrm{ng} / \mathrm{dl}$ on day 15 . A subsequent decline to $63 \mathrm{ng} / \mathrm{dl}$ occurred between 15-30 days and a slight rise was observed thereafter.

\section{DISCUSSION}

These data indicate marked and dynamic changes in mean SMG NGF and EGF contents and concentrations during postnatal life in the male mouse. They are the first reported observations of the ontogeny of both NGF and EGF in the same SMG measured by sensitive and specific RIA techniques. The present results are in general agreement with those of Bynny et al. (9) for EGF and Aloe and Levi-Montalcini (3) for NGF. Both groups reported exponential increases in SMG EGF and NGF concentrations from 15-20 days of age through adulthood. The NGF data of Aloe and Levi-Montalcini (3) were derived by bioassay whereas we report RIA concentrations. Both the bioassay and RIA methods measure either free $\beta$ NGF or the 7S (MW 140,000) storage complex. SMG NGF in gland homogenates has been shown to exist predominantly as the large molecular weight complex (38). SMG EGF is present both in the $6000 \mathrm{MW}$ form and the $74,000 \mathrm{MW}$ complex (39).

Our results confirm the exponential increases in SMG NGF and EGF reported earlier $(3,9)$ and in addition, on the basis of
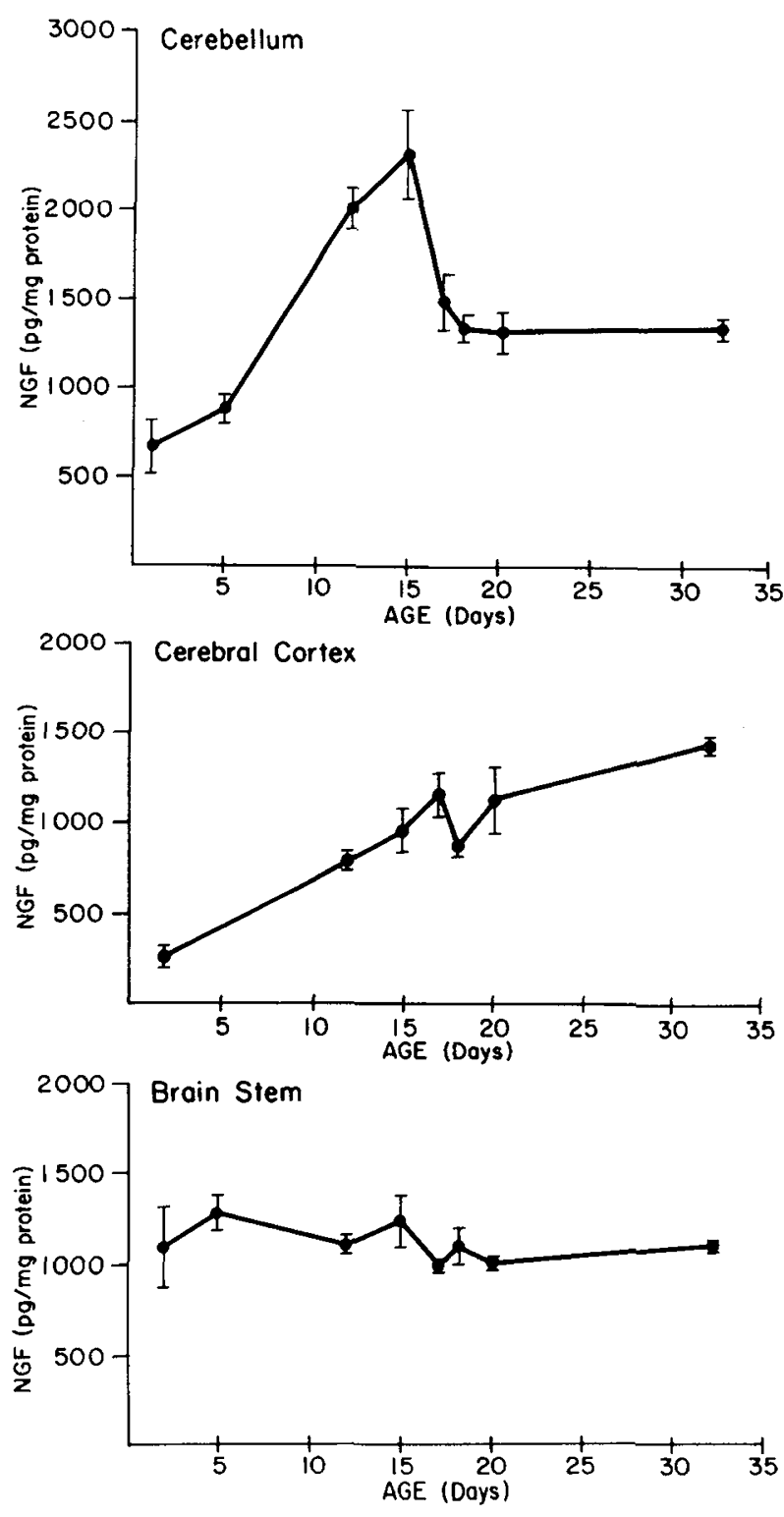

Fig. 3. Ontogeny of NGF in male mouse cerebellum, cerebral cortex and brain stem. All data points comprise the mean \pm SE. See text for details of pooling methods. 


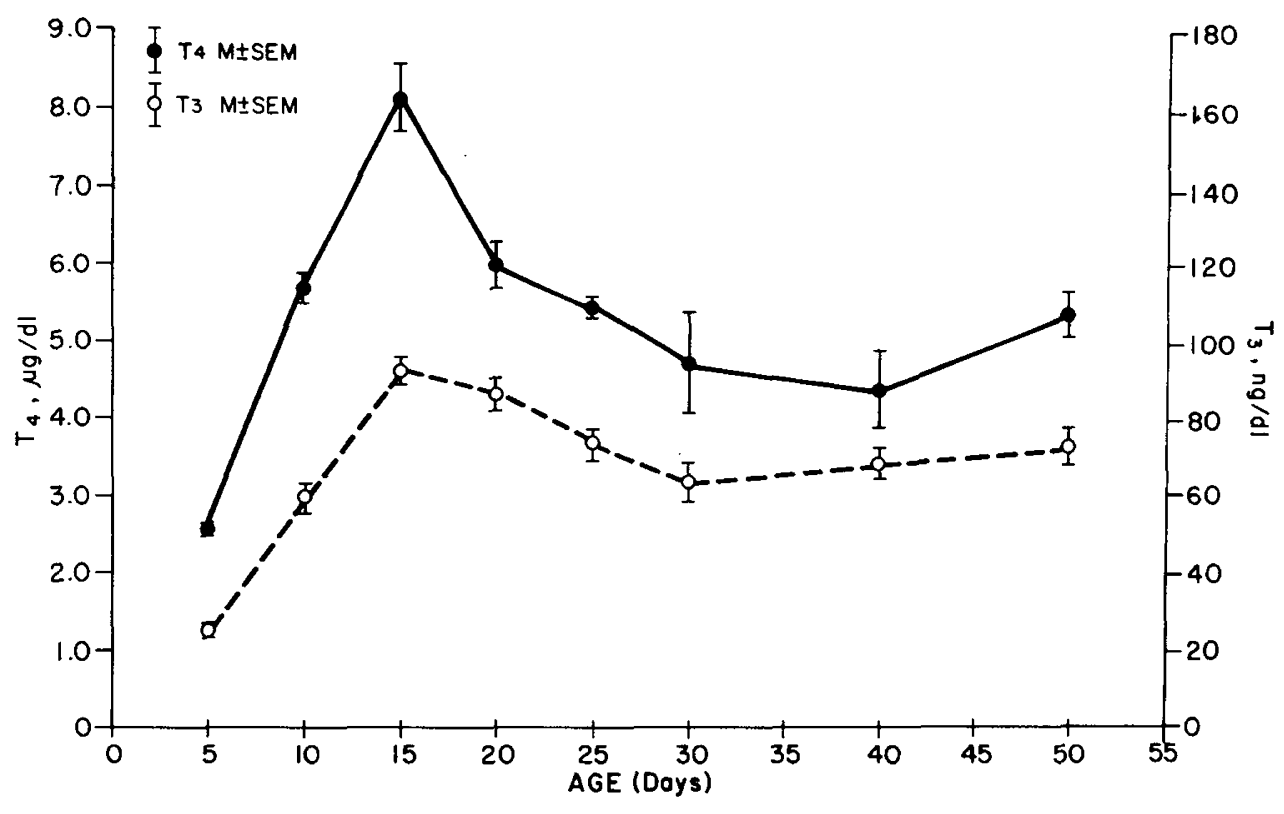

Fig. 4. Ontogeny of serum $\mathrm{T} 3\left(\mathrm{O}_{--} \mathrm{O}\right)$ and $\mathrm{T} 4\left(\mathrm{C}_{-}\right)$concentrations in the newborn mouse. All data points comprise the mean $\pm \mathrm{SE}$. See text for details of pooling methods.

more frequent samplings, demonstrate three phases of increase (Fig. 1, 2). In the first phase (11-18 days of age), NGF and EGF contents increased 2.4- and 2.3-fold respectively. During the second phase (18-32 days), 9845- and 7805-fold increases in NGF and EGF concentrations were noted. A third phase showed progressive increases of 6.5-fold between 32-60 days of age; thus, there is marked similarity in the patterns of accumulation of both NGF and EGF in the SMG. Both the initial decreases and subsequent increases in NGF and EGF concentrations during postnatal life are strikingly concordant; moreover, mean SMG NGF and EGF concentrations in the adult (60-day-old) mouse are similar (Fig. 1 and 2) in agreement with earlier reports (26, 39). The factors responsible for the observed developmental patterns of NGF and EGF in SMG may be similar, although the predominant factor(s) during early postnatal life may well be different from those operative in mature animals.

The present ontogentic studies of NGF in brain tissue represent the first data available in any species. The molecular form of the brain NGF is not known; the present RIA reacts with $\beta$ NGF or the larger storage molecule. In a recent report, we have demonstrated NGF bioactivity in adult mouse brain homogenate, but direct comparisons of bioactivity and RIA concentrations were not possible due to the semiquantitative nature of the bioassay and the low NGF concentrations (33). It is not known whether brain NGF levels have any significance in brain maturation. We have reported earlier that thyroid hormone administration increases NGF concentrations in brain tissue in neonatal as well as adult mice $(37,40)$. Aloe and colleagues $(4)$ have reported recently that neonatal mice, which received NGF antiserum injection in utero, demonstrate hypothyroid-like behavior in the neonatal period.

Assuming that brain NGF levels are related to brain development, it is of interest to relate the NGF concentrations changes to the developmental morphologic events. The 3-fold rise and subsequent fall in cerebellar NGF concentrations (Fig. 3) occur at a postnatal age immediately after the time of maximum cell replication in the cerebellar external granular layer in rats and mice (19) and correponding to the onset of increased inward granule cell migration (21), elongation of parallel fibers (20), synaptogenesis (28), and further dendritic arborization and cellular differentiation. In the cerebral cortex (Fig. 3), the continuously progressive 5 -fold increase in NGF concentration during the first 4 postnatal wk appears to parallel the migration to the cortex of late forming cerebral neurons from the periventricular germinal zone. During this period there is a progressive increase in density of cortical axons, dendritic arborizations, and synaptogenesis (18).

The relatively flat developmental profile for postnatal mouse brain stem NGF (Fig. 3) is compatible with the fact that murine brain stem development occurs prenatally in order to accomodate the vegitative functions of the suckling animal. In both the mouse (30) and rat (5-8), neurons from nuclei at various levels of the brain stem have been shown to originate well before parturition. Brain stem growth in both the neonatal mouse and rat is less pronounced than in other brain areas, suggesting that cellular proliferation and differentiation are nearing completion during the neonatal period. Thus the three major brain regions have different time tables of development, and NGF concentrations in each region correspond with the ontogenetic period related to cellular differentiation. It must be reemphasized, however, that a role for NGF in brain development remains entirely speculative.

It is of interest that NGF levels in the brain tissues do not parallel the ontogenetic profile of NGF in SMG. The significance of SMG NGF is not known (27). The SMG may contribute to circulating NGF concentrations, but sialectomy does not markedly reduce circulating NGF (RIA) levels (27); moreover, NGF does not cross the blood-brain barrier (1), and reports indicate that CNS cells from both human (29) and rat (23) produce NGF in vitro. The NGF levels measured in brain tissue presumably reflect local production. The observation of nonparallel changes in SMG and brain NGF concentrations observed in the present study are compatible with this hypothesis. The levels of SMG and brain NGF are approximately the same order of magnitude during the first 1-2 wk of life but by 30 days, SMG levels exceed brain concentrations by some three orders of magnitude.

Our data (Fig. 4), describing the developmental profile of serum $\mathrm{T} 4$ and $\mathrm{T} 3$ in the mouse, are the only available ontogenetic data for thyroid hormones in this species. The data for mouse correspond in general to data described for rat $(15,36)$ where serum total and free T4 and T3 concentrations are low at birth and increase progressively during the first $3-4$ wk of postnatal life (15, 36). In the mouse, (Fig. 4) the peak of serum T3 concentration appears to coincide at age 15 days with that of $\mathrm{T} 4$, whereas in the rat T3 levels are maximum at 3-4 wk of age (15) compared with a T4 peak at age 2 wk (15). We and others have shown that thyroid hormones markedly increase NGF concentrations in adult as well as neonatal mouse SMG $(3,38,39)$. In earlier reports we 
have documented that thyroid hormone administration increases EGF levels in SMG of adult mice (39) and increases NGF levels in adult and neonatal mouse brain $(37,40)$. The timing of the increase in circulating thyroid hormone levels in the mouse is compatible with the view that thyroid hormones may play a role in the pronounced increase in SMG NGF and EGF concentrations between 11 and 32 days of age, as well as the increases in cerebellar NGF between 2 and 15 days and the progressive increase in cerebral NGF levels between 2 and 32 days. Further studies are necessary to prove this hypothesis.

NGF and EGF concentrations also are known to be androgen dependent and levels of both are higher in adult male than in adult female SMG $(10,22,27)$; however, serum testosterone levels remain below $1 \mathrm{ng} / \mathrm{ml}$ before 26 days gestation (14) only increasing to adult levels between 4-12 wk of age. Thus, circulating androgens are not likely to be a major factor in the marked increase in SMG NGF and EGF between 18-32 days. Androgen may, however, play a role in the third phase increases in SMG NGF concentrations.

\section{REFERENCES AND NOTES}

1. Angeletti, R. H., Angeletti, P. U., and Levi-Montalcini, R.: Selective accumulation of $\left[{ }^{125} \mathrm{I}\right]$ labelled nerve growth factor in sympathetic ganglia. Brain Res., 46: 421 (1972).

2. Angeletti, R. H. and Bradshaw, R. A.: The amino acid sequence of $2.5 S$ nerve growth factor from the mouse submaxillary gland. In: Nerve Growth Factor and its Antiserum, Zaimis, E., Ed. p. 35 (Anthalone Press, University of London, 1972).

3. Aloe, L. and Levi-Montalcini, R.: Comparative studies on testosterone and Lthyroxine effects on the synthesis of nerve growth factor in mouse submaxillary salivary glands. Exp. Cell Res., 125: 15 (1980).

4. Aloe, L., Cozzari, C., Calissano, P., and Levi-Montalcini, R.: Somatic and behavioral postnatal effects of fetal injections of nerve growth factor antibodies in the rat. Nature, 291: 413 (1981).

5. Altman, J. and Bayer, S. A.: Development of the brain stem in the rat. I. Thymidine-radiographic study of the time of origin of neurons of the lower medulla. J. Comp. Neurol., 194: 1 (1980).

6. Altman, J. and Bayer, S. A.: Development of the brain stem in the rat. II. Thymidine-radiographic study of the time of origin of neurons of the upper medulla, excluding the vestibular and auditory nuclei. J. Comp. Neurol., 194: 37 (1980).

7. Altman, J. and Bayer, S. A.: Development of the brain stem in the rat. III Thymidine-radiographic study of the time of origin of neurons of the vestibular and auditory nuclei of the upper medulla. J. Comp. Neurol., 194: 877 (1980).

8. Altman, J. and Bayer, S. A.: Development of the brain stem in the rat. IV. Thymidine-radiographic study of the time of origin of neurons in the pontine region. J. Comp. Neurol., 194: 9051980.

9. Bynny, R. L., Orth. D. N., and Cohen. S.: Radioimmunoassay of epidermal growth factor. Endocrinology, 90: 1261 (1972).

10. Bynny, R. L., Orth. D. N., Cohen, S., and Doyne, E. S.: Epidermal growth factor: effect of androgens and adrenergic agents. Endocrinology, 95: 776 (1974).

11. Chopra, I. J.: A radioimmunoassay for measurement of thyroxine in unextracted serum. J. Clin. End. 34: 938 (1972).

12. Chopra, I. J., Ho, R. S., and Lam, R. W.: An improved radioimmunoassay of triiodothyronine in serum: its application to clinical and physiologic studies. J. Lab. Clin. Med., 80: 729 (1972)

13. Cohen, S. and Taylor, J. M.: Epidermal growth factor: chemical and biological characterization. Recent Prog. Horm. Res. 30: 533 (1974).

14. Dunn, J. F. and Wilson, J. D.: Developmental study of androgen responsiveness in the submandibular gland of the mouse. Endocrinology, 96: 1571 (1975).

15. Dussault. J. H. and Labrie, F.: Development of the hypothalamic-pituitarythyroid axis in the neonatal rat. Endocrinology, 97: 1321 (1975).

16. Hirata, Y. and Orth, D. N.: Concentrations of epidermal growth factor, nerve growth factor, and submandibular gland renin in male and female mouse tissues and fluids. Endocrinology, 105: 1382 (1979).

17. Ishii, D. N. and Shooter, E. M.: Regulation of nerve growth factor synthesis in mouse submaxillary glands by testosterone. J. Neurochem., 25: 843 (1975)
18. Jacobsen, M.: Develop. Neurobiology, 2nd Edition, p. 62, 63, 74. (Plenum Press, New York, New York 1978).

19. Lauder, J. M.: The effects of early hypo- and hyperthyroidism on the development of rat cerebellar cortex. III. Kinetics of cell proliferation in the external granular layer. Brain Res., 126: 31 (1977).

20. Lauder, J. M.: Effects of early hypo- and hyperthyroidism on development of rat cerebellar cortex. IV. The parallel fibers. Brain Res., 142: 25 (1978).

21. Lauder, J. M.: Granule cell migration in developing rat cerebellum. Influence of neonatal hypo- and hyperthyroidism. Dev. Biol., 70: 105 (1979).

22. Levi-Montalcini, R. and Angeletti, P. U.: Nerve growth factor. Physiol. Rev., 48: 534 (1968).

23. Longo, A. M.: Synthesis of nerve growth factor in rat glioma cells. Dev. Biol., 65: 260 (1978).

24. Lowry, O. H., Rosebrough, N. J., Farr, A. L., and Randall, R. J.: Protein measurement of the Folin-phenol reagent. J. Biochem., 143: 265 (1951).

25. Mobley, W. C., Schenker, A., and Shooter, E. M.: Characterization and isolation of proteolytically modified nerve growth factor. Biochemistry, 15: 5543 (1976).

26. Murphy, R. A., Pantazis, N. J., and Papstavros, M.: Epidermal growth factor and nerve growth factor in mouse saliva: a comparative study. Dev. Biol., 71: 356 (1970).

27. Murphy, R. A., Saide, J. D., Blanchard, M. H., and Young, M.: Nerve growth factor in mouse serum and saliva: role of submandibular gland. PNAS USA, 74: 2330 (1977)

28. Nicholson, J. L. and Altman, J.: Synaptogenesis in the rat cerebellum: effects of early hypo- and hyperthyroidism. Science, 176: 530 (1972).

29. Norrgren, G., Ebendal, T., Belew, M., Jacobson, C. O., and Porath, J.: Release of nerve growth factor by human glial cells in culture. Exp. Cell Res., 130: 31 (1980).

30. Rodier, P. M.: Chronology of neuron development: animal studies and their clinical implications. Dev. Med. Child. Neurol.,, 22: 525 (1980).

31. Savage, C. R., Jr. and Cohen, S.: Epidermal growth factor and a new derivative. Rapid isolation procedures and biological and chemical characterization. $J$. Biol. Chem., 247: 7609 (1972).

32. Schwab, M. E., Stockel, K., and Thoenen, H.: Immunocytochemical localization of nerve growth factor (NGF) in the submandibular gland of adult mice by light and electron microscopy. Cell Tissue Res., 169: 289 (1976).

33. Scott, S. M., Tarris, R. H., Eveleth, D., Weichsel, M. E., Jr., and Fisher, D. A.: Bioassay detection of mouse nerve growth factor (mNGF) in the brain of adult mice. J. Neurosci. Res. 6: 653 (1981)

34. Server, A. C. and Shooter, E. M.: Comparison of the arginine esteropeptidases associated with the nerve and epidermal growth factors. J. Biol. Chem., 251: 165 (1976).

35. Van Noorden, S., Heitz, P., Kasper, M., and Pearse, A. G.: Mouse epidermal growth factor: light and check on microscopical localization by immunocytochemical staining. Histochemistry, 52: 329 (1977).

36. Walker, P., DuBois, J. D., and Dussault, J. H.: Free thyroid hormone concentrations during postnatal life in the rat. Pediatr. Res., 14: 247 (1980).

37. Walker, P., Weichsel, M. E., Jr., Fisher, D. A., Guo, S. M., and Fisher, D. A. Thyroxine increases nerve growth factor concentration in adult mouse brain, Science, 204: 427 (1979).

38. Walker, P., Weichsel, M. E., Jr., Guo, S. M., Fisher, D. A., and Fisher, D. A. Radioimmunoassay for mouse nerve growth factor (NGF). Effects of thyroxine administration on tissue NGF levels. Brain Res., 186: 331 (1980).

39. Walker, P., Weichsel, M. E., Jr., Hoath, S. B., Poland, R. E., and Fisher, D. A.: Effect of thyroxine, testosterone and corticosterone on nerve growth factor (NGF) and epidermal growth factor (EGF) concentrations in female mouse submaxillary gland. Dissociation of NGF and EGF responses. Endocrinology, 109: 582 (1981).

40. Walker, P., Weil, M. L., Weichsel, M. E., Jr., and Fisher, D. A.: Effect of thyroxine on nerve growth factor concentration in neonatal mouse brain. Life Sci. 28: 1777 (1981).

41. Weichsel, M. E., Jr.: Unpublished observation.

42. Requests for reprints should be addressed to: Dr. M. E. Weichsel, Jr., Department of Pediatrics, A-17, Harbor-UCLA Medical Center, 1000 West Carson Street, Torrance, CA 90509.

43. This research was supported in part by USPHS grants HD 11303 and HD 04772 from the National Institute of Child Health and Human Development. Dr. Walker was a fellow of the Medical Research Council of Canada. Current address is Departmente d'Endocrinologie et Metabolisme, Le Centre Hospitalier de L'Universite Laval, 2705 boul Laurier, Quebec, Quebec, GIV 4G2, Canada.

44. Received for publication July $20,1981$.

45. Accepted for publication January 8, 1982. 